\title{
Simultaneous Determination of Gatifloxacin and Ambroxol Hydrochloride in a Tablet Formulation by Liquid Chromatography
}

\author{
Lakshmana Prabu S*, M. Srinivasan, S Thiagarajan and Queeni Marina \\ Department of Pharmaceutical Technology, Anna University Tiruchirappalli, Tiruchirappalli 620024 India
}

\begin{abstract}
A rapid and accurate liquid chromatographic method has been developed for the simultaneous determination of gatifloxacin (GFC) and ambroxol hydrochloride (AMB) in a tablet formulation. Chromatographic separation of the two drugs was achieved on a Phenomenex column $(200 \mathrm{~mm} \times 4.6 \mathrm{~mm}, 5 \mu \mathrm{m})$. The mobile phase consisting of a mixture of $0.1 \mathrm{M}$ phosphate buffer adjusted to $\mathrm{pH} 5.5$ and acetonitrile in the ratio of $55: 45$ was delivered at a flow rate of $1.0 \mathrm{ml} /$ min. Detection was performed at $254 \mathrm{~nm}$ using UV detector. The retention time for GFC was around 2.2 and AMB was around $4.5 \mathrm{~min}$; separation was complete in less than $10 \mathrm{~min}$. The linear regression analysis data for the calibration plots showed good linear relationship in the concentration range of $10-200 \mu \mathrm{g} / \mathrm{ml}$ and $10-100 \mu \mathrm{g} / \mathrm{ml}$ and correlation coefficient was found to be 0.9992 and 0.9983 for GFC and AMB respectively. The method was validated for accuracy, precision and recovery studies. Statistical analysis proved the method was precise, reproducible, selective, specific, and accurate for analysis of GFC and AMB. The wide linearity range, sensitivity, accuracy, short retention time, and simple mobile phase imply the method is suitable for routine quality control of formulation products.
\end{abstract}

Keywords: Gatifloxacin; Ambroxol Hydrochroride; Simultaneous Determination; Chromatography; Pharmaceuticals

\section{Introduction}

Gatifloxacin(GFC)ischemically 1-cyclopropyl-6-fluoro-1,4-dihydro8-methoxy-7- (3-methyl-1-piperazinyl)-4-oxo-3-quinolinecarboxilic acid [1] has broader spectrum of antibacterial activity than the older fluoroquinolones and shows good activity against gram +ve and gram -ve microorganisms [2]. Ambroxol Hydrochloride (AMB) is chemically trans-4-(2-amino 3,5-dibromobenzyl)amino-cyclohexanol, as hydrochloride, is used to reduces bronchial hyper-reactivity, stimulates cellular surfactant production, increases the amount of antibiotic penetration and thus reduces daily dose of gatifloxacin and exhibits anti-inflammatory properties as well [3]. These two drugs are not official in any pharmacopoeia; GFC and AMB are used in dual drug therapy for the treatment of upper respiratory tract infection for adults. Some methods can be found for the individual determination of roxithromycin and ambroxol hydrochloride. High performance liquid chromatography [4] and LC/ESI-MS/MS [5] methods have been reported for the estimation of gatifloxacin in dosage forms and from human plasma. Methods available for the determination of ambroxol hydrochloride include capillary electrophoresis [6-8], spectrometry [9], gas chromatography $[10,11]$ and $\mathrm{LC}$ with potentiometric detection [12], MS detection [13] and UV detection [14-18] methods have been reported for the estimation of ambroxol $\mathrm{HCl}$.

In recent years pharmaceutical preparations containing both these drugs have been available commercially. However, no references have been found for simultaneous determination of GFC and $\mathrm{AMB}$ in pharmaceutical preparations. Liquid chromatography with UV detection is often preferred in ordinary laboratories because of its wide suitability and availability. The reported methods for the individual determination of the drugs cannot be easily applied for the simultaneous determination of both drugs in the formulation owing to their large differences in physic-chemical properties. The present paper describes a rapid and accurate LC method for the simultaneous determination of GFC and $\mathrm{AMB}$ in the tablet formulation.

\section{Materials and Methods}

\section{Chemicals}

GFC and AMB were obtained as the gift samples from Aristo Pharma Ltd., India. HPLC grade methanol, acetonitrile and water (triple distilled) were procured from Qualigens Fine Chemicals, Mumbai, India.

\section{Chromatographic conditions}

Chromatography was performed on a (Shimadzu HPLC Class 10A Series) equipped with two LC-10AT pumps with a variable UVVis detector SPD-10A. Samples $(20 \mu \mathrm{l})$ were injected by means of a Rheodyne injector fitted with a $20 \mu$ l loop. Class LC-10AT series, version 5. 03 were employed for data collecting and processing. A Phenomenex RP-C18 column $(250 \mathrm{~mm} \times 4.6 \mathrm{~mm}$ i.d.; Particle size $5 \mu$ ) was used for separation. The mobile phase consisting of 0.1 $\mathrm{M}$ phosphate buffer adjusted to $\mathrm{pH} 5.5$, acetonitrile $(55: 45 \% \mathrm{v} / \mathrm{v})$ was delivered at a flow rate of $1.0 \mathrm{ml} / \mathrm{min}$. The mobile phase was filtered through a $0.45 \mu \mathrm{m}$ membrane and degassed for $30 \mathrm{~min}$ in an ultrasonic bath. Analysis was performed at ambient temperature and detection was performed at $254 \mathrm{~nm}$. The injection volume was $20 \mu \mathrm{l}$.

\section{Method development}

Preparation of stock solution from the bulk drug: Standard stock

*Corresponding author: Lakshmana Prabu S Department of Pharmaceutical Technology, Anna University Tiruchirappalli, Tiruchirappalli 620024, India, E-mail: slaxmanvel@gmail.com

Received August 30, 2010; Accepted September 27, 2010 Published Septembe 30, 2010

Citation: Prabu SL, Srinivasan M, Thiagarajan S, Marina Q (2010) Simultaneous Determination of Gatifloxacin and Ambroxol Hydrochloride in a Tablet Formulation by Liquid Chromatography. Pharm Anal Acta 1:110. doi:10.4172/2153-2435.1000110

Copyright: @ 2010 Prabu SL, et al. This is an open-access article distributed unde the terms of the Creative Commons Attribution License, which permits unrestricted use, distribution, and reproduction in any medium, provided the original author and source are credited. 
solution of $500 \mu \mathrm{g} / \mathrm{ml}$ of GFC and AMB were prepared by dissolving separately in $50 \mathrm{ml}$ of HPLC methanol in $100 \mathrm{ml}$ volumetric flask, the volume was made up to mark with the same. Standard solutions were prepared by dilution of the stock solution with mobile phase to give the final concentration range of $10-200 \mu \mathrm{g} / \mathrm{ml}$ and $10-100 \mu \mathrm{g} / \mathrm{ml}$ for GFC and AMB respectively.

Sample preparation: Twenty tablets were weighed accurately. The average weight was determined and then ground to a fine powder. A quantity equivalent to $75 \mathrm{mg}$ of AMB and $400 \mathrm{mg}$ of GFC were transferred to a $100 \mathrm{ml}$ volumetric flask. The contents were ultrasonicated for $15 \mathrm{~min}$ with $50 \mathrm{ml}$ of HPLC methanol and made up to the mark with same. The resulting solution was allowed to settle for about an hour, and the supernatant was suitably diluted to give the desired concentration with mobile phase. The solution was filtered using $0.2 \mu \mathrm{m}$ membrane filter. The area under the curve and the drug content per tablet (on an average weight basis) was calculated.

Precision: Intra-day and inter-day accuracy and precision of the assay samples containing $(80,100$ and $120 \mu \mathrm{g} / \mathrm{ml})$ for GFC and $(40,60$ and $80 \mu \mathrm{g} / \mathrm{ml}$ ) for AMB were analyzed six times in the same day (intraday) and for three consecutive days by different analysts (inter-day).

Specificity: The specificity of the method was assessed by analyzing standard drug, pharmaceutical product and placebo and comparing the Retention time of the standard with that of the sample to determine whether the pharmaceutical product and placebo led to interfere.

Accuracy as Recovery studies: Recovery studies were done at three different levels. The pre-analyzed samples were spiked with $80,100,120 \mu \mathrm{g} / \mathrm{ml}$ and $40,60,80 \mu \mathrm{g} / \mathrm{ml}$ of pure GFC and AMB respectively, and the mixtures were reanalyzed by the proposed method. Percentage recovery was calculated from the amount of drug found in the solution.

Robustness: By introducing small but deliberate changes in the mobile phase $\mathrm{pH}(0.1)$, mobile phase composition $( \pm 2.0 \%$ ), detection wavelength $( \pm 5.0 \mathrm{~nm})$, flow rate $( \pm 10.0 \%$ of absolute value) robustness of the described method was studied.

\section{Results}

The suitability of the mobile phase was decided on the basis of the various trials. The composition of the mobile phase for development of chromatographic method was optimized by testing different solvent mixtures of varying polarity. After several trials, finally a mobile phase consisting of a mixture of phosphate buffer $\mathrm{pH}$ 5.5 and acetonitrile, in the ratio of $(55: 45 \% \mathrm{v} / \mathrm{v})$ was adopted, which

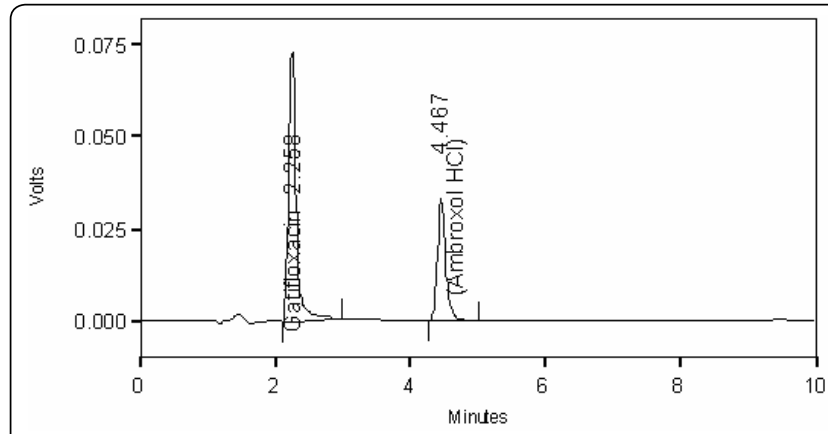

Figure 1: A typical chromatogram of a sample solution containing gatifloxacin and ambroxol $\mathrm{HCl}$.

\begin{tabular}{|l|l|l|l|l|}
\hline \multirow{2}{*}{ Actual conc. $(\mu \mathrm{g} / \mathrm{ml})$} & \multicolumn{3}{l|}{ Intra-day precision } & \multicolumn{2}{l|}{ Intra-day precision } \\
\cline { 2 - 5 } & SD & $\%$ RSD & SD & \%RSD \\
\hline GFC & 0.72 & 0.91 & 0.85 & 1.08 \\
\hline 80 & 1.31 & 1.34 & 1.29 & 1.33 \\
\hline 100 & 1.25 & 1.06 & 1.30 & 1.11 \\
\hline 120 & \multicolumn{5}{|l|}{} \\
\hline AMB & 0.39 & 1.02 & 0.51 & 1.33 \\
\hline 40 & 0.59 & 1.02 & 0.74 & 1.29 \\
\hline 60 & 0.65 & 0.83 & 0.94 & 1.21 \\
\hline 80 &
\end{tabular}

Table 1: Intra and inter day precision of HPLC method ${ }^{\text {. }}$

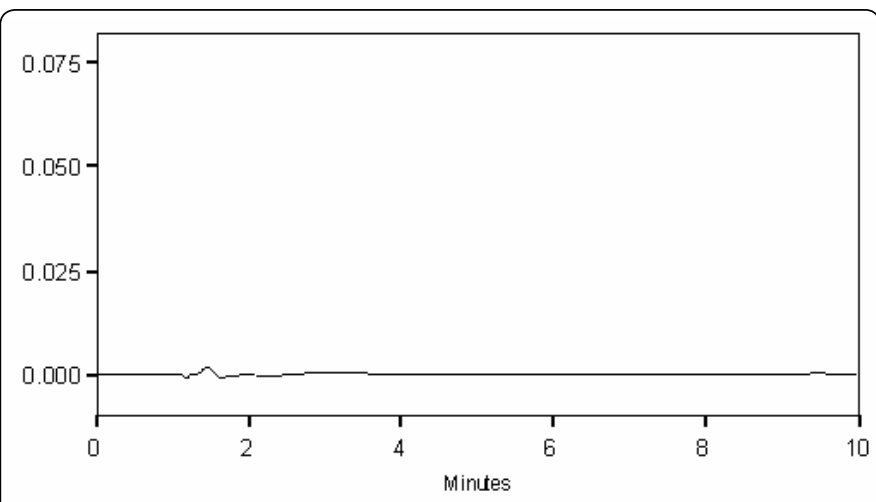

Figure 2: Chromatogram obtained from placebo.

\begin{tabular}{|l|l|l|}
\hline Amount added $(\mu \mathrm{g} / \mathrm{ml})$ & Amount recovered $(\mu \mathrm{g} / \mathrm{ml})$ & Recovery $(\%)$ \\
\hline GFC & 79.16 & 98.95 \\
\hline 80 & 98.79 & 98.79 \\
\hline 100 & 118.66 & 98.88 \\
\hline 120 & 39.51 & 98.79 \\
\hline AMB & 59.49 & 99.15 \\
\hline 40 & 79.27 & 99.08 \\
\hline 60 & &
\end{tabular}

${ }^{a} n=6$

Table 2: Recovery studies ${ }^{\mathrm{a}}$

produces good resolution, reasonable retention and acceptable peak shape for both drugs. The retention time for GFC was around 2.2 and AMB was around $4.5 \mathrm{~min}$. Separation was complete in less than 10 min which is shown in (Figure 1).

A set of six solutions of GFC and AMB at concentrations ranging from 10 to $200 \mu \mathrm{g} / \mathrm{ml}$ and 10 to $100 \mu \mathrm{g} / \mathrm{ml}$ were prepared. Each sample was analyzed in triplicate; calibration curve was constructed by plotting the peak area against concentration using linear regression analysis. The correlation coefficient was found to be 0.9992 and 0.9980 for GFC and AMB respectively.

The intra-day precision of the developed LC method was determined by preparing the tablet samples of the same batch in six determinations with three concentrations. The R.S.D. of the assay results, expressed as a percentage of the label claim, was used to evaluate the method precision. The obtained R.S.D. values were $1.10 \%$ for GFC and $1.17 \%$ for AMB. The inter-day precision was also determined by assaying the tablets in triplicate per day for consecutive 3 days, which was found to be 0.96 and $1.28 \%$ for GFC and $\mathrm{AMB}$, respectively. The results are shown in (Table 1).

The specificity of the method was confirmed by comparing the Retention time of standard with that of GFC and AMB in the marketed formulation. The blank chromatogram obtained from the placebo is shown in (Figure 2).

The developed method was used to quantify GFC and AMB in 
tablet dosage; tablets of $400 \mathrm{mg}$ of GFC and $75 \mathrm{mg}$ of AMB label claim were analyzed and the average drug content was found to be $99.26 \%$ and $98.86 \%$ for GFC and AMB respectively for labeled amount. It may therefore be inferred that degradation of GFC and AMB had not occurred in the formulation that were analyzed by this method. The recovery results are shown in (Table 2). The mean recoveries were found to be $98.88 \pm 0.08$ and $99.01 \pm 0.19$ for GFC and AMB respectively.

The standard deviation of peak areas was calculated for each parameter such as small changes in the variations of $\mathrm{pH}$ of the mobile phase $( \pm 0.1)$, mobile phase composition $( \pm 2.0 \%)$, wavelength of detection $( \pm 5.0 \mathrm{~nm})$, flow rate $( \pm 10.0 \%$ of absolute value). The $\%$ R.S.D. was found to be less than $2 \%$.

\section{Discussion}

The development of HPLC methods for the determination of drugs has received considerable attention in recent years because of their importance in the quality control of drugs and drug products. The primary goal in developing this $\mathrm{LC}$ method is to achieve simultaneous determination of GFC and AMB in the compound formulation under common conditions that are applicable for the routine quality control of this product in ordinary laboratories. consisting of a mixture of phosphate buffer pH 5.5 and acetonitrile, in the ratio of $(55: 45 \% \mathrm{~V} / \mathrm{V})$ was adopted, which produces good resolution, reasonable retention and acceptable peak shape for both drugs.

The results show that an excellent correlation existed between peak area and concentration range between 10 to $200 \mu \mathrm{g} / \mathrm{ml}$ and 10 to $100 \mu \mathrm{g} / \mathrm{ml}$ for GFC and AMB respectively. Repeatability study was carried out at three different concentration levels of 80, 100 and $120 \mu \mathrm{g} / \mathrm{ml}$ and 40,60 and $80 \mu \mathrm{g} / \mathrm{ml}$ for GFC and AMB respectively. The repeatability results revealed that the developed method is having good repeatability.

The specificity of the method was confirmed by the absence of interfering peaks from the excipients commonly present in the tablets and therefore be interred that degradation of GFC and AMB had not occurred in the formulation that were analyzed by this method. Hence the developed method is specific and selective.

Accuracy and recovery study results revealed that the developed method can be used for determination of GFC and $A M B$ in pharmaceutical formulation. The low \% RSD value for analysis of GFC and AMB in marketed formulation indicated the suitability of this method for routine analysis of GFC and AMB in pharmaceutical dosage forms.

Small deliberate changes in the chromatographic condition did not affect the method and the low values of \% RSD results revealed that the robustness of the method.

\section{Conclusion}

The developed HPTLC method combined with densitometry was found suitable for determination of duloxetine hydrochloride in bulk drug and marketed solid dosage formulation without any interference from the excipients. Statistical analysis proves that the method is repeatable and selective for the analysis of duloxetine hydrochloride. Its advantages are low cost of reagents, speed and simplicity of sample treatment, satisfactory precision and accuracy.

\section{References}

1. Budavari S, O Neil JM, Smith A, Heckelman EP (2001) The Merck Index. 13 Ed Merck \& Co Whitehouse Station NJ: 777.

2. Perry CM, Ormrod D, Hurst M, Onrust SV (2002) Gatifloxacin: A review of its use in the management of bacterial infections. Drugs 62: 169-207.

3. Gillissen A, Nowak D (1988) Characterisation of N-acetylcysteine and ambroxol in anti-oxidant therapy. Respir Med 92: 609-623.

4. Liang H, Kays MB, Sowinski KM (2002) Separation of levofloaxacin ciprofloxacin, gatifloxacin, moxifloxacin, trovafloxacin and cinoxacin by HPLC: application to levofloxacin determination in human plasma. J Chromatogr $\mathrm{B}$ Analyt Technol Biomed Life Sci 772: 53-63.

5. Vishwanathan K, Bartlett MG, Steward JT (2001) Determination of gatifloxian in human plasma by liquid chromatography/electrospray tandem mass spectroscopy. Rapid Commun Mass Spectrom 15: 915-919.

6. Pospisilova M, Polasek M, Jokl V (2001) Determination of ambroxol or bromhexine in pharmaceuticals by capillary isotachophoresis. J Pharm Biomed Anal 24: 421-428.

7. Perez-Ruiz T, Martinez-Lozano C, Sanz A, Bravo E (2000) Sensitive method for determination of ambroxol in body fluids by capillary electrophoresis and fluorescence detection. J Chromatogr B Biomed Sci Appl 742: 205-210.

8. Perez-Ruiz T, Martinez-Lozano C, Sanz A, Bravo E (1997) Determination of bromhexine and ambroxol in pharmaceutical dosage forms, urine and blood serum. Journal of Chromatography B 692: 199-205.

9. Dincer Z, Basan H, Goger NG (2003) Quantitative determination of ambroxol in tablects by derivative UV spectroscopy method and HPLC. J Pharm Biomed Anal 31: 867-872.

10. Colombo L, Marcucci F, Marini GM, Poerfederici P, Mussini E (1990) Determination of ambroxol in biological material by gas chromatography with electron capture detection. J Chromatogr 530: 141-147.

11. Schmid J (1987) Assay of ambroxol in biological fluid by capillary gas liquid chromatography. J Chromatogr 414: 65-75.

12. Bazylak G, Nagels LJ (2003) Simultaneous high-through put determination of clenbuterol, ambroxol and bromhexine in pharmaceutical formulation by HPLC with potentiometric detection. J Pharm Biomed Anal 32: 887-903.

13. Kim H, Yoo JY, Han SB, Lee HJ, Lee KR (2003) Determination of ambroxol in human plasma using LC-MS/MS. J Pharm Biomed Anal 32: 209-216.

14. Heinanen M, Barbas C (2001) Validation of HPLC method for the quantification of ambroxol hydrochloride and benzoic acid in syrup as pharmaceutical formulation stress test for stability evaluation. J Pharm Biomed Anal 24: 10051010.

15. Koundorellis JE, Malliou ET, Broussali TA. (2000) HPLC determination of ambroxl in the presence of different preservatives in pharmaceutical formulations. J Pharm Biomed Anal 23: 469-475.

16. Nobilis M, Pastera J, Svoboda D, Kvetina J, Acek K. (1992) High-performance liquid chromatographic determination of ambroxol in human plasma. Jour Chromatogr 581: 251-255.

17. Brizzi $V$, Pasetti U (1990) HPLC determination of ambroxol in pharmaceuticals J Pharm Biomed Anal 8: 107-109.

18. Kuchekar BS, Shinde GS, Naikawadi IT, Todkar KJ, Kharade SV (2003) Spectrophotometric estimation of ambroxol hydrochloride in tablets. Indian J Pharm Sci 65: 193-195. 